\title{
Detecting areas of vegetation change in the Densu River Basin, Ghana
}

\author{
S. Mantey, N. D. Tagoe \& M. S. Aduah \\ Department of Geomatic Engineering, \\ University of Mines and Technology, Ghana
}

\begin{abstract}
The objectives of this study were to monitor vegetation change patterns and to determine how land management practices have contributed to vegetation change in the Densu Basin.

The procedures employed involve independently classifying multi-temporal images using a hybridized classification method after geo-referencing and coregistering images. A land cover map of the basin was pre-loaded onto a Juno SB hand-held GPS receiver and geo-referenced for ground-truth delineation of vegetation classes. Readings were taken for thirty-three (33) geographical positions and corresponding classes of vegetation to enhance classification accuracy.
\end{abstract}

The Normalized Difference Vegetation Indices (NDVI) of Advanced Very High Resolution Radiometer (AVHRR) images were monitored for variations in the NDVI values due to seasonal changes. The effects due to phenology were then minimized using the Normalized Difference Senescence Vegetation Index (NDSVI) method.

The Principal Component Analysis (PCA) technique was used to identify possible areas of vegetation depletion in the basin. The trend of change was further determined by a NDVI image differencing method by setting threshold values that best discriminate per pixel change.

The result of this study revealed significant loss of vegetation cover in the basin. For example whereas open forest was dominant in the northern sector with a total coverage area of $490 \mathrm{~km}^{2}$ in the 1985 classification, the same vegetation type disappeared by 1991 and was replaced by scattered trees with dense herbs. There was a further decrease of forest cover between 1991 and 2000 from 332 
$\mathrm{km}^{2}$ in 1991 to $273 \mathrm{~km}^{2}$ in 2000 representing a loss of $59 \mathrm{~km}^{2}$. Also, between 2000 and 2002, there was a decrease of $41 \mathrm{~km}^{2}$ in vegetation cover.

In conclusion, this study provides information to assist land managers to gather ecological information about the basin to help in planning and managing the basin's resources.

Keywords: hybridized classification, phenology, AVHRR, PCA, NDVI, NDSVI.

\section{Introduction}

Increasing human activities and climatic conditions have resulted in a substantial change in the vegetation type in the Densu Basin. The basin is among the fastest growing and most populated basins in Ghana and therefore can be described as urban or suburban. The distribution of vegetation on the earth's surface is of wide significance at all spatial scales (Rees [1]).

Urban vegetation abundance may also influence air quality and human health (Wagrowski and Hites [2]), because trees provide abundant surface area for sequestration of particulate matter and ozone. Vegetation also experiences both short and long term phenological changes and may be sensitive to subtle changes in environmental conditions. The Densu Basin is the most environmentally stressed basin in the country. Land use activities within the basin are varied and impact negatively on the vegetation cover as well as the river body. These include deforestation activities in the upper parts and extensive farming practices in middle parts of the basin. This is leading to depletion of vegetation cover and increasingly exposing the Densu River to evapotranspiration.

The Weija Dam constructed in the southern part of the basin contributes an important source of water to the people living in Accra and Ga districts in the Greater Accra. Visits to the dam and its environs however showed that the vegetation cover along the banks is depleting, thereby exposing the river body and the Weija Dam to evapotranspiration. There is therefore the need to protect the vegetation cover in the Densu River Basin in order to avoid further deterioration since vegetation is a key indicator for overall environmental conditions. Also, change in vegetation is a useful means for recognizing changes in other environmental factors.

\section{The study area}

The Densu River Basin lies within longitude $1^{\circ} 30^{\prime} \mathrm{W}-1^{\circ} 45^{\prime} \mathrm{W}$ and latitude $5^{\circ} 45^{\prime} \mathrm{N}$ $-6^{\circ} 15^{\prime} \mathrm{N}$ and covers an estimated area of $2488 \mathrm{~km}^{2}$. The basin may be divided into three sub-areas as shown in Figure 1;

1. The Nsawam catchment extends over $1510 \mathrm{~km}^{2}$.

2. The area between Nsawam and Weija extends over an area of $950 \mathrm{~km}^{2}$.

3 . The area lying between Weija and the sea makes up the remaining 28 $\mathrm{km}^{2}$.

The Densu River takes its source from the Atewa-Atwiradu mountain range close to Kibi and flows for about $116 \mathrm{~km}$ southwards into the Weija Dam before 


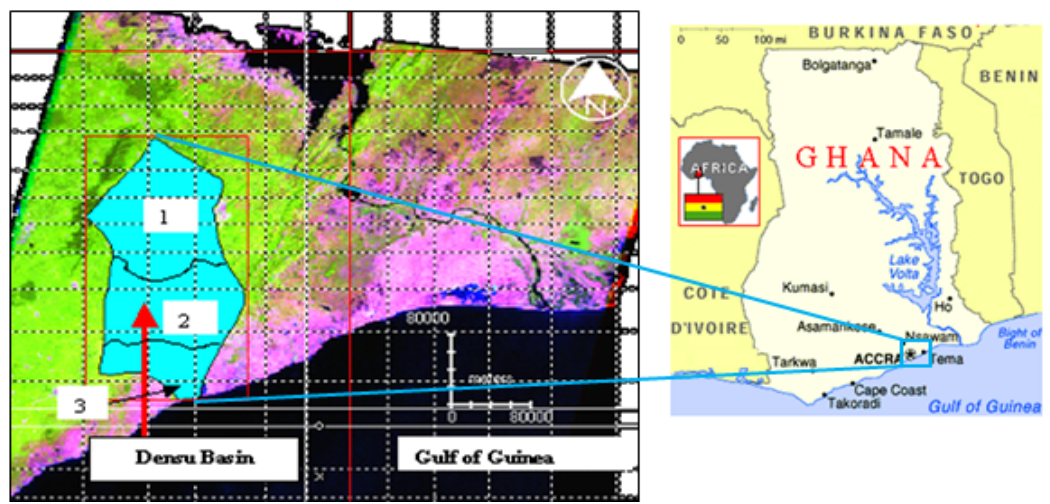

Figure 1: Vector overlay of study area.

entering the Atlantic Ocean in the Gulf of Guinea through the Sakumo-Lagoon. It covers nine (9) administrative districts and runs through about fifty-four (54) towns and villages including urban settlements of Koforidua, Suhum, Nsawam, Mangoase, Akwadum, New Asuoyaa and Weija.

Although the Densu Basin consists mainly of rural settlements, the river runs close to the nation's capital, one regional capital and three district capitals. Population density in the basin is among the highest in the country.

\section{Topography and soil geology}

The vegetation of the basin consists of the coastal savanna thicket and grassland to the south and the north a moist semi-deciduous forest over preventing excessive leaching and evaporation during the wet and dry seasons respectively.

The semi-deciduous zone used to contain some of the countries timber trees. However, due to rapid expansion of the cocoa industry, very little of the original forest remain. Most of what is left is secondary forest. Farmlands within this zone have resulted in the appearance of grass species in the secondary forest, which is now referred to as derived savanna. The land cover map showing the vegetation types in the basin is shown in Figure 2.

Soils in the basin are mainly well-drained, friable, porous, loamy savanna ochrosols mostly red or reddish brown in colour. They are generally low in nutrients especially phosphorus and nitrogen (Dickson and Benneh [3]). However in the northern part of the basin are forest ochrosols red or reddish brown, orange brown with adequate amount of nutrients.

\section{Climate}

Climate in the Densu Basin may be classified as humid and wet with a mean annual rainfall of about $2000 \mathrm{~mm}$, with two rainy seasons and two dry seasons. 


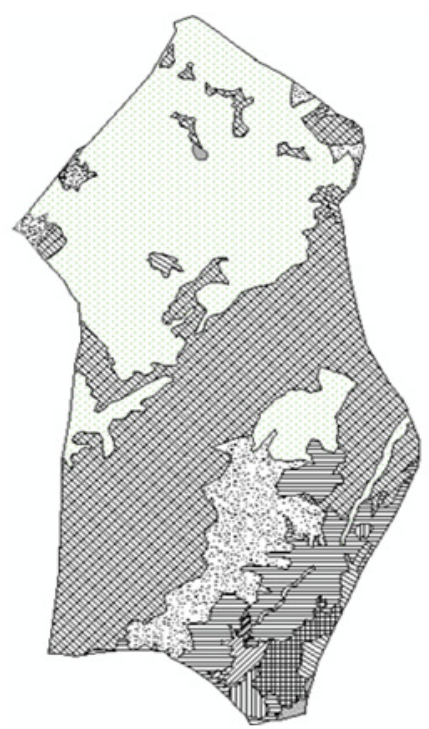

Landcover types in the Densu Basin

E G Grass/herb with/without scattered trees ( $0-5$ trees/ha)

$\square$ Lagoon

Moderately closed tree ( $>15$ trees/ha) canopy with herb and bush cover

Moderately dense herb/bush with scattered trees ( $<15$ trees/ha)

目 Mosaic of thickets grass with/without scattered trees

Oas Open forest ( $<60 \%$ )

曲 Open savanna woodland ( $<25$ trees/ha)

$\square$ Planted cover

ए] Reservoir

$\square$ Riverine savanna vegetation

Settlement

III) Shrub thicket with/without trees

WW Wetland

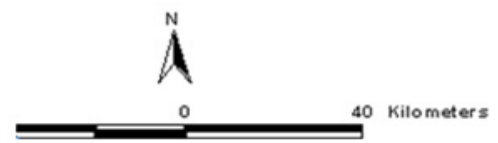

Figure 2: $\quad$ Land cover map of Densu Basin (source: survey of Ghana, 1985).

The major raining season starts from March to July and the minor season from September to the end of November. The dry seasons are pronounced in between December and February. This period is the most severe with negligible rainfall and high temperature. Mean temperatures generally range between $26^{\circ} \mathrm{C}$ and $30^{\circ} \mathrm{C}$.

\section{Data acquisition, processing, validation and analysis}

\subsection{Data acquisition}

Four Landsat images were used in this study. The dates 1985, 1991 and 2002 were ordered from the Tropical Rain Forest Information Centre (TRFIC) in the binary sequential format (BSQ) whilst the date 2000 was downloaded in the format of LIG from the Global Land Cover Facility (GLCF) website: http:/glcfapp.umiacs.md.edu.

The four Landsat images with path/row of 193 and 056 respectively, cover the Densu Basin and details are provided in Table 1.

\section{Table 1: Description of datasets.}

\begin{tabular}{|l|c|c|c|c|}
\hline $\begin{array}{l}\text { Acquisition } \\
\text { date }\end{array}$ & Sensor ID & $\begin{array}{l}\text { Pixel } \\
\text { spacing }\end{array}$ & Elevation/zenith & $\begin{array}{l}\text { Processing } \\
\text { level }\end{array}$ \\
\hline April 7, 1985 & Landsat TM5 & $28.5 \mathrm{~m}$ & $57.210 / 88.010$ & BSQ \\
\hline January 10, 1991 & Landsat TM4 & $28.5 \mathrm{~m}$ & $44.880 / 130.320$ & BSQ \\
\hline February 4, 2000 & Landsat ETM+ & $28.5 \mathrm{~m}$ & $51.864 / 125.990$ & LIG \\
\hline December 26, 2002 & Landsat ETM+ & $28.5 \mathrm{~m}$ & $49.248 / 136.735$ & BSQ \\
\hline
\end{tabular}


Additional data acquired for the purpose of this study included 10-day composite monthly AVHRR images of $1 \mathrm{~km}$ resolution obtained from the Land Processes Distributed Active Archive Centre (LPDAAC) and Goddard Earth Sciences Data and Information Services Centre (GES DISC) with the following parameters: (northernmost latitude $=11^{0}$; westernmost longitude $=3^{0}$; southernmost latitude $=5^{0}$ and easternmost $=1^{0}$ ).

The rest are land cover map, map of settlements in the basin, topographic map of scale 1:50,000 and map of rivers draining the basin; all obtained from the Department of Geomatic Engineering, KNUST - Ghana. Data on population in the basin was also obtained from the Centre for Remote Sensing and GIS (CERGIS) University of Ghana.

\subsection{Pre-processing}

In comparative analysis of multi-temporal images taken by different sensors, the conversion of digital numbers to radiance values is an inevitable step. Every sensor has its own calibration parameters in recording digital numbers and therefore the same digital numbers recorded by different sensors will represent different radiance values. Since this study aims at comparing multi-temporal images for changes, converting digital numbers to radiance units was unavoidable in order to minimize bias in judgement of observed changes. The digital numbers were converted to radiance values for the ETM+ and TM images as explained by Chander et al [4] using equations (1) and (2) as follows:

$$
\mathrm{L}_{\lambda}=\left(\frac{L M A X_{\lambda}-L M I N_{\lambda}}{Q_{\text {calmax }}-Q_{\text {calmin }}}\right)\left(Q_{\text {cal }}-Q_{\text {calmin }}\right)+L M I N_{\lambda}
$$

or

$$
G_{\text {rescale }} * Q_{\text {cal }}+B_{\text {rescale }}
$$

where:

$$
\begin{gathered}
G_{\text {rescale }}=\frac{L M A X_{\lambda}-L M I N_{\lambda}}{Q_{\text {calmax }}-Q_{\text {calmin }}} \\
B_{\text {rescale }}=L M I N_{\lambda}-\left(\frac{L M A X_{\lambda}-L M I N_{\lambda}}{Q_{\text {calmax }}-Q_{\text {calmin }}}\right) Q_{\text {calmin }}
\end{gathered}
$$

\subsubsection{Atmospheric correction}

For a study involving a multi-year comparison of images, the atmosphere will undoubtedly vary from time to time. It is therefore necessary to correct the radiance values recorded at the sensor for the effects of the atmosphere. Various methods of atmospheric correction are used to correct for this effect.

In this study atmospheric correction by dark pixel was found to be useful due to the identification of reliable dark objects such as the Weija Dam and the Gulf of Guinea which occupied a large number of pixels in the scenes of the basin. The correction was carried out using the spatial modeler tool in Erdas Imagine software. The path radiances were estimated for the dark objects for each band and then used as correction values. 
Further, in order to minimize scene variability, the radiance values computed above were then converted to apparent reflectance on the earth surface taking into account earth-sun distance and the solar zenith.

\subsubsection{Geo-referencing}

Geometric referencing is the transformation of a remotely sensed data so that it has the scale and projection properties of a map (Mather [5]). Geo-referencing is essential in image pre-processing as various remote sensing sensors do not correctly reproduce the stationary grid on the earth.

Typically geometric referencing is performed in order to overlay images from the same area but taken at different dates, combine data from different sensor systems and to integrate an image with digital information from other sources in a GIS.

Besides the ETM+ 2000 image from the GLCF which was geo-referenced in the UTM referenced system, the other three images ordered from TRFIC as described above, were not geo-referenced. The images were first projected in UTM coordinate system and the spheroid of WGS84, as in the header file. The images were then re-projected into the Ghana War Office spheroid and Transverse Mercator projection as used in the Ghana coordinate system.

The images were subsequently re-sampled using the nearest neighbour method. This technique was chosen among other methods because the nearest neighbour technique retains the original pixel value which is an important consideration in discriminating between vegetation classes.

Similar ground control points were identified in both the topographic map of scale 1:50,000 and the images. These were used for image-to-map registration and also to co-register images.

\subsection{Controlling error and improving accuracy}

Some form of distortions in the scanned topographic map is unavoidable; however the effect of distortion was minimized by avoiding the extreme edges in the geo-referencing and registration process.

The effect of distortion in the map was in the order of $0.3 \%$ of the length measured from the grid width and therefore the effect was negligible. For example, it has been reported that a registration accuracy of less than one-fifth of a pixel is required to achieve a change detection error within 10\% (Dai and Khorram [6]). This study analysed a multi-temporal imagery and therefore ensured that co-registration of the images were within 0.5 pixels since a larger pixel offset will reduce the ability for the images to be overlaid correctly. The root mean square errors (RMSE) of all the images were less than 0.5 pixels.

\subsection{Minimizing change due to phenology}

Vegetation is sensitive to weather factors such as rainfall, humidity, temperature and as a result, responds to changes by altering their seasonal growth patterns.

Phenology is therefore a contributor to vegetation change and therefore monitoring it from start to end of growing season is of great importance in 
interpreting remotely sensed data. The impact of vegetation phenology may be partially reduced by selecting data belonging to the same time of the year. It is however difficult to obtain multi-date data of the same time of the year, especially for tropical areas where cloud cover is common. In order to discern vegetation change due to disturbance, the phenological change effect is estimated and used to minimize the effect on the imagery.

To estimate and minimize phenological change effectively, the phenological signatures of the study area were monitored for twelve months for the years 1985, 1991 and 2000 using NDVI values of a 10-day composite AVHRR images. Four different locations in the basin least likely to be disturbed by human activities were selected from the NDVI AVHRR images for the separate years 1985, 1991 and 2000. Their NDVI values were computed for each of the locations and plotted with the monthly NDVI image composites. Graphical plots reveals that NDVI values are high between May, June and July, which are relatively the wet seasons. Conversely, in the other months, because of the low amount of rainfall, these periods showed generally lower NDVI values when compared to the wet period.

This affirms the fact that there may be changes in vegetation cover, which may be due to seasonal changes rather than disturbance. It is therefore worthwhile to minimize vegetation change as a result of phenology in order to detect changes that might be caused purely by disturbance in vegetation studies when the image dates available are close to both seasons.

To minimize the effect of phenology in this study, the Normalized Difference Vegetation Index (NDVI) and Normalized Difference Senescence Vegetation Index (NDSVI) were computed and used to minimize the effect of phenology as follows:

Step one: The NDVI'S of all the images were computed using equation (3); (i.e 1985, 1991, 2000 and 2002).

$$
\text { NDVI }=(\text { TM4 }- \text { TM3) } /(\text { TM4 }+ \text { TM3 })
$$

Step two: The $\mathrm{NDSVI}_{1}$ of image acquired in the dry season was estimated using equation (4); (i.e. the January, 1991 image).

$$
\text { NDSVI }=(\text { TM5 - TM3)/TM5 + TM3) }
$$

Step three: The $\mathrm{NDSVI}_{2}$ of image acquired in growing season (wet season) was estimated using equation (4); (i.e. the April, 1985 image).

Step four: The difference between $\mathrm{NDSVI}_{1}$ and $\mathrm{NDSVI}_{2}$ was determined. (This result is the overall change in phenology).

The phenological change in the multi-temporal imagery is minimized by subtracting the overall change due to phenology obtained earlier from the NDVI'S of all the imagery determined in equation (3).

Having subtracted the phenological change from the computed NDVI of all the images, the effect of phenological change becomes insignificant though not totally eliminated.

This approach was found to be useful in minimizing the phenological change since the short wave infrared spectral band Thematic Mapper five (TM5) situated 
near the water regions of the electromagnetic spectrum can be used to enhance signals from senescent vegetation.

The reflective-infrared band (Band 5: 1.55-1.75 $\mu \mathrm{m}$ (mid-infrared)) is sensitive to turgidity, thus the amount of water in plants. Turgidity is useful in drought (dry season) studies and plant vigour (growing season) studies.

The spectral response in the short wave infrared will increase due to loss of water in the leaf. The short wave infrared bands (TM5 and TM7) are therefore useful in detecting phenological vegetation change.

\subsection{GPS field validation}

In order to delineate ground truth vegetation classes and to evaluate vegetation change, a Juno SB hand-held GPS Receiver of 2 metre accuracy was used to obtain geographical coordinate information in the field with the corresponding vegetation classes. These readings were done for thirty-three (33) geographical positions and corresponding classes of vegetation cover recorded. The geographical coordinates recorded from the hand-held GPS in (WGS84 spheroid) were transformed to the Ghana War Office spheroid and subsequently converted to ground coordinates. The use of the GPS to obtain ground truth vegetation classes corresponding to ground coordinates was to aid in the selection of training data to perform supervised classification of the imagery.

\subsection{Hybridized classification}

First, the unsupervised classification was performed for the four Landsat images and then supervised classification. The ground coordinates obtained for the corresponding vegetation classes were overlaid on the unsupervised classified image. This was done to identify the unknown classes that correspond to the ground coordinates for the supervised classification. In all, thirty-three (33) ground coordinates with known vegetation classes were overlaid on the unsupervised image to extract the training data for the supervised classification.

The land cover map obtained from the survey of Ghana (1985) was also used as a check to ensure accuracy in the classification process. The parametric rule used for the supervised classification was the maximum likelihood method since it assumes that a statistical model exists which describes the classes in the attributes space.

The identification of classes was done by digitizing polygons to define the areas of interest. The next stage was to extract the spectral signatures of the identified training classes so as to collect all the pixels defined in the area. Having extracted the spectral signatures, the statistical properties of the training areas were defined to ensure that the classes were distinct from other classes identified.

In the classification process, eight vegetation types were identified and monitored in the basin. They include; shrub thicket, open savanna woodland, open forest, moderately dense herb with scattered trees, grass and herbs with and without scattered trees, mosaics of thickets and grass with scattered trees. 


\subsection{Accuracy assessment}

Accuracy assessment was carried out after classification of each image since the classification will not be complete without it. Accuracy report was generated after each image classification. The result of the accuracy assessment in this study was reported in the form of error matrix as presented by Story and Congalton [7] in their description of the error matrix.

The overall accuracies obtained ranged between $89.02 \%$ and $94.48 \%$. Anderson et al. [8] stated that accuracies of $85 \%$ are required for land-use data for resource management. The accuracy results for the classifications could therefore be described as reliable for further analysis.

\subsection{Principal Component Analysis (PCA)}

Using principal component analysis in change detection of multi-date images requires that the multi-date images to be analysed are merged. The objective of using PCA in this study was to identify areas of possible changes in the multitemporal images. The thematic images of 1985, 1991, 2000 and 2002 were merged in the pairs of; 1985 and 1991, 1991 and 2000, 2000 and 2002.

The bands used in merging the images were bands 2,3 and 4 . These bands were selected because they are sensitive to mass of vegetation.

The PCA method was useful in detecting areas of possible vegetation change in the basin.

\subsection{NDVI image differencing}

Image differencing was performed with the spatial modular function tool in Erdas Imagine software. The mean and standard deviations of each dataset were used to determine threshold values for change. Two standard deviations were used as the threshold point.

The area between the mean; \pm 2 standard deviations was considered to represent no change, the area above represents positive change and the area below represents negative change. On the basis of these threshold values, the image was reclassified into the following three categories, minimum to lower threshold, lower to upper threshold and upper threshold to maximum value respectively. The minimum to lower threshold represented negative change, lower to upper threshold represented no change and upper threshold to maximum value represented positive change in NDVI.

The results of the image differencing were then normalized based on the actual observed high and low values and then converted to the 8-bit range of 0 255. Thus, in general, places that have not changed were observed to occur in the middle of the distribution, with areas that have brighter or darker portions occurring in the ends of the distribution.

The NDVI image differences were converted to grid format in order to determine and analyze the percentage of grid counts in each class of change or no change areas. The percentage grid counts for each category of vegetation classes were recorded. Areas of positive change (increase in vegetation) were 
assigned green colour whilst negative changes (decrease in vegetation) were assigned red colour. The areas with no significant changes were represented by white-grey colour.

\section{Results and discussions}

The result of 1985-1991 image difference is presented in Figure 6. The changes identified were categorized into three groups. It was observed that a total area of $1258.7 \mathrm{~km}^{2}$ of the basin had decreased in vegetation cover thus representing $51 \%$ of the total area whilst about $33 \%$ of the basin's total area had increased in vegetation cover (see Table 2). The area of about $400 \mathrm{~km}^{2}$ remained unchanged.

Figure 7 shows the results for the 1991-2000 image difference analysis. Changes in this period revealed similar trend of vegetation change as observed between 1985 and 1991. About 58\% of the basin's area was recorded as decreasing in vegetation cover compared to 51\% recorded between 1985 and 1991 (see Table 3). The results for 2000-2002 recorded little difference in vegetation change over the previous analysis between 1991 and 2000 (see Figure 8).

Table 2: $\quad$ Statistical results of (1985-1991) NDVI-Image differencing.

\begin{tabular}{|c|c|c|c|}
\hline & \multicolumn{3}{|c|}{$1985-1991$} \\
\hline Colour Codes & Grid counts & Area/km ${ }^{2}$ & Area (\%) \\
\hline & 6004755 & 399.96 & 16.08 \\
\hline & 12450961 & 829.33 & 33.33 \\
\hline & 18897168 & 1258.70 & 50.59 \\
\hline & 37352885 & 2488.00 & 100.00 \\
\hline
\end{tabular}

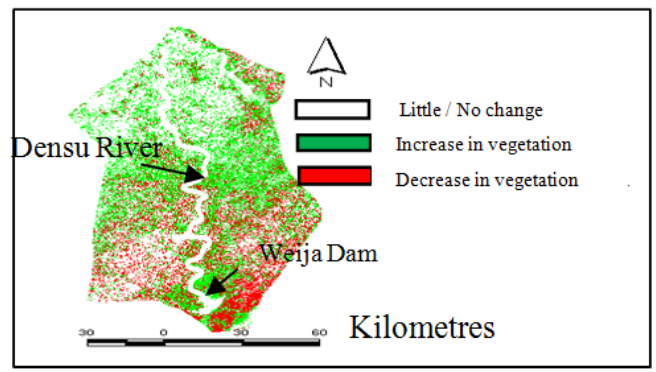

Figure 3: $\quad$ NDVI-Image difference for 1985-1991.

Table 3: $\quad$ Statistical results of (1991-2000) NDVI-Image differencing.

\begin{tabular}{|c|c|c|c|}
\hline & \multicolumn{3}{|c|}{$1991-2000$} \\
\hline Colour Codes & Grid counts & Area $/ \mathrm{km}^{2}$ & Area (\%) \\
\hline \hline & 4407640 & 293.58 & 11.80 \\
\hline \hline & 11329130 & 754.61 & 30.33 \\
\hline \hline & 21616115 & 1439.80 & 57.87 \\
\hline Total & 37352885 & 2488.00 & 100.00 \\
\hline
\end{tabular}




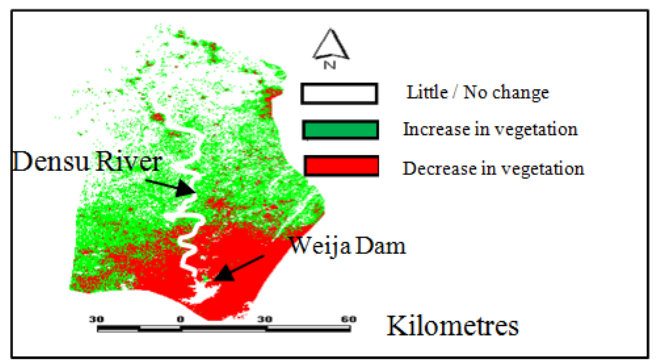

Figure 4: NDVI-Image difference for 1991-2000.

Table 4: $\quad$ Statistical results of (2000-2002) NDVI-Image differencing.

\begin{tabular}{|c|c|c|c|}
\hline & \multicolumn{3}{|c|}{$2000-2002$} \\
\hline Colour Codes & Grid counts & Area $/ \mathrm{km}^{2}$ & Area (\%) \\
\hline & 4314295 & 287.34 & 11.55 \\
\hline \hline & 10914513 & 726.99 & 29.22 \\
\hline & 22124077 & 1473.64 & 59.23 \\
\hline Total & 37352885 & 2488.00 & 100.00 \\
\hline
\end{tabular}

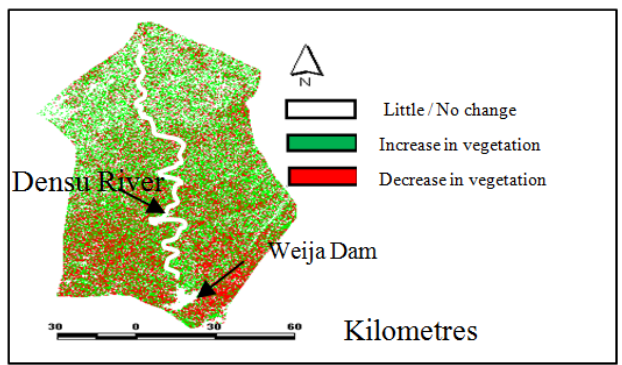

Figure 5: NDVI-Image difference for 2000-2002.

A total area of $287 \mathrm{~km}^{2}$ remained undisturbed in vegetation between 2000 and 2002. This represents $12 \%$ of the vegetation cover whilst an area of $1474 \mathrm{~km}^{2}$ recorded a downward trend in vegetation cover (see Table 4).

\section{Conclusion and findings}

Vegetation in the basin is over exploited and is leading to its degradation. The periods between 1991-2000 and 2000-2002 recorded the highest lost of vegetation cover representing 58\% and 59\% respectively. Also, results from this study showed that open forest cover decreased from an area of $420 \mathrm{~km}^{2}$ to 230 $\mathrm{km}^{2}$ between 1985 and 2002 .

The causes of vegetation degradation in the basin was found to be uncontrolled exploitation of natural resources, rapid expansion of urban settlements and bad agricultural practices. 


\section{References}

[1] Rees, W.G., The Remote Sensing Data Book, Cambridge University Press, 1999.

[2] Wagrowski, D. M., and Hites, R. A., Polycyclic aromatic hydrocarbon accumulation in urban, suburban and rural vegetation, Environmental Science \& Technology, 31, 1, 279-282, 1997.

[3] Dickson, K.B. and Benneh, G., A New Geography of Ghana, Longman, London, p. 18, 1970.

[4] Chander, G., Markham, B.L., Helder, D.L., "Summary of Current Radiometric Calibration Coefficients for Landsat MSS, TM, ETM+, and EO-1 ALI Sensors", Remote Sensing of Environment, 113, 893 - 903, 2009.

[5] Mather, P. M., Computer Processing of Remotely-Sensed Images, An Introduction, Wiley \& Sons, Chichester, 352 p, 1987.

[6] Dai, X.L., Khorram, S., The effects of image misregistration on the accuracy of remotely sensed change detection, IEEE Transaction on Geoscience and Remote Sensing, 36, 1566-1577, 1998.

[7] Story, M. and Congalton, R. G., Accuracy Assessment: A User's Perspective. Photogrammetric Engineering \& Remote Sensing 52(3):397399, 1986.

[8] Anderson, G.L., Hanson, J.D. and Haas, R.H., Evaluating Landsat Thematic Mapper derived vegetation indices for estimating above-ground biomass on semi arid rangelands, Remote Sensing of Environment, 45:165-175, 1993. 